\begin{tabular}{c|c|c|c|}
\cline { 2 - 3 } & REVISTA SABERES APUDEP & Volumen 3 Número 2 & \\
& ISSN L 2644-3805 & \\
\hline
\end{tabular}

\title{
EL FLETAMENTO MARITIMO COMO FACILITADOR DEL COMERCIO INTERNACIONAL
}

\author{
MARITIME FLETAMENT AS FACILITATOR OF INTERNATIONAL TRADE
}

\author{
Yira Wong \\ Universidad de Panamá, Centro Regional Universitario de Colón. Área Gestión \\ Marítima. \\ carmenmanchong@gmal.com
}

Francisco Valdés

Universidad de Panamá, Centro Regional Universitario de Colón. Área Gestión

Marítima.

igondola@yahoo.com

https://orcid.org/0000-0002-3391-0145

\section{RESUMEN}

El entorno económico actual que con permanente inclusión de nuevas tecnologías produce un ambiente comercial internacional en donde la importación y exportación se ha convertido en un fenómeno de grandes proporciones que se caracteriza por nuevas formas comerciales de actuación en los grandes bloques globales, requiere del conocimiento de formas y procesos actualizados, en donde Contrato de Fletamento Marítimo cumple con una labor de facilitación en el intercambio de bienes comerciales, como herramienta eficaz en el desplazamiento de la carga a través del buque, como artefacto de transportación por excelencia de la actividad comercial marítima que cumple con eficacia la posibilitación del transporte marítimo a través del régimen de fletamentos. El Fletamento de buques, constituye una institución de carácter jurídico de las más antiguas, se remonta al derecho babilónico y "su finalidad primordial es la explotación del buque mediante la dedicación de transportes ajenos" (Mira Galiani Jaime, 2010, pág. 218), bien colocándolo a disposición de los interesados para que se realicen dichos transportes, o sin hacer entrega de la nave, limitándose a recoger las mercancías entregadas por los 


\begin{tabular}{|c|c|c|}
\cline { 2 - 3 } & REVISTA SABERES APUDEP & Volumen 3 Número 2 \\
\hline
\end{tabular}

remitentes en el puerto de carga para ser transportados al puerto de destino y entrega a los respectivos consignatarios. Básicamente, se trata de la contratación del buque entre cargadores y navieras. Los cargadores podrán escoger el tipo de buque que más se adapta a las necesidades de la carga a transportar y las opciones son el transporte en régimen de fletamentos y transporte por línea regular.

PALABRAS CLAVE: Fletamento Marítimo, Economía de Transporte, Panamá

\section{ABSTRACT}

The current economic environment that with the permanent inclusion of new technologies produces and international commercial environment where import and export has become a phenomenon of great proportions characterized by new commercial forms of action and processes, where the Maritime Charter Contract performs a facilitation work in the exchange of commercial goods, as an effective tool in the movement of cargo though the ship, as a transportation device par excellence of the maritime commercial activity that effectively fulfills the possibility of maritime transport through the charter system. The chartering of ships, constitutes one of the oldest legal institutions, dates back to Babylonian las and "its primary purpose is the operation of the ship though the dedication of third-party transport" (Mira Galiani Jaime, 2010 , p. 218), either placing it at the disposal of the interested parties to carry out said transport, or without making delivery of the ship, limiting itself to picking up the goods delivered to the respective consignees. Basically, it is about the contracting of the ship between shippers and shipping companies. Loaders will be able to choose the type of ship that best suits the needs of the cargo to be transported and the options are chartering and regular line transportation.

KEY WORDS Maritime Charter, Transport Economy, Panama 


\begin{tabular}{|c|c|c|}
\cline { 2 - 3 } & REVISTA SABERES APUDEP & Volumen 3 Número 2 \\
\hline
\end{tabular}

\section{INTRODUCCIÓN}

Este documento precisa describir y desarrollar las condiciones inherentes al fletamento de buques como estrategia del Comercio Internacional y del Negocio Marítimo, destacando que constituye un facilitador del Comercio Internacional que se reviste de importancia indispensable con base en las condiciones globales para el desplazamiento de la carga en el mundo.

Conceptos básicos

Flete es el contrato básico del comercio marítimo. Nombre que también se aplica a la carga transportada.

Fletante La persona que se obliga a hacer el transporte.

Fletador la persona que contrata la utilización del buque para el transporte o directamente el transporte de sus mercaderías.

Comisionista de transporte intervención de un tercero que, por cuenta ajena, contrata el transporte con el fletante o porteador.

Fletamento incluye no sólo la contratación directa del transporte, sino también la indirecta del transporte contratando la utilización del buque para tal fin; y ello sea contratando la utilización del buque por entero o sólo por una parte, por un viaje o por varios, o por tiempo determinado.

Al referirnos al Comercio Internacional a través del Negocio Marítimo nos corresponde indicar que se trata de una de las actividades más globalizada en ámbito del transporte de carga y de personas. Produce altos promedios de facturación y comercialización con un número plural de servicios. Con relación al negocio marítimo y su aporte al Comercio Internacional en materia de Fletamento, indicamos que conlleva un contrato de alquiler de nave por el tiempo de carga para trasportación de mercancía por vía marítima, sin el cual el desplazamiento de bienes seria dificultoso, riesgoso e ineficiente. 


\begin{tabular}{|c|c|c|}
\cline { 2 - 3 } & REVISTA SABERES APUDEP & Volumen 3 Número 2 \\
\hline
\end{tabular}

En este documento se abordan los siguientes aspectos: destacando lo antiguo de la actividad de fletamento en el negocio marítimo, con fines de acceder al desarrollo competitivo actual de del transporte marítimo internacional a través de los procesos de fletamento. Seguidamente nos introduciremos al ambiente marítimo desde el enfoque de fletamento de buques, bajo la óptica de sus tres actores principales: Armador o Armador Disponente, Fletador y Bróker y como el resulta de su interacción en el mercado o fuera de él, se dará un contrato de fletamento el cual obligará al Fletador principalmente a pagar el flete y a tener lista y dispuesta para su carga la mercancía en las fechas acordadas y obligará principalmente al armador a tener el buque listo y dispuesto para la carga y transporte de dicha mercancía en las fechas acordadas, realizando el Bróker la labor de intermediación entre ambos.

La metodología aplicada en esta investigación según el enfoque descriptivo permitirá analizar primero, información aproximada a los hechos observados en el fletamento de buques. Luego, se realizarán indagaciones referenciales para el discernimiento de las estrategias de fletamento de buques en el negocio marítimo.

\section{DESARROLLO}

\subsection{Marco Normativo del Transporte Marítimo de Carga}

Con relación al transporte de carga marítima, el marco legal internacional señala:

El Convenio de las Naciones Unidas sobre el Contrato de Transporte Internacional de Mercancías Total o Parcialmente Marítimo, adoptado por la Asamblea General de las Naciones Unidas el 11 de diciembre de 2008, establece un régimen legal uniforme y moderno en relación con el Transporte Internacional de Mercancías, al regular los derechos y las obligaciones de los cargadores, los porteadores y los destinatarios sujetos a un contrato de transporte de puerta a puerta que comprenda un tramo internacional por vía marítima. Con el nuevo Convenio se reverdecen los anteriores que regían el Transporte Internacional de mercancías por mar, sean las Reglas de La Haya de 1924 y sus Protocolos de 1968 y 1979; Las Reglas de Hamburgo del 31 de marzo de 1978. 


\begin{tabular}{|c|c|c|}
\cline { 2 - 3 } & REVISTA SABERES APUDEP & Volumen 3 Número 2 \\
\hline
\end{tabular}

(Convenio de las Naciones Unidas sobre el Contrato de Transporte Internacional de Mercancías Total o Parcialmente Marítimo "Reglas de Rotterdam" 2008)

Para situarnos un poco, vamos a continuar presentando algunas definiciones sobre que es un flete, como el concepto que condiciona y valida el negocio marítimo de fletamento:

El flete marítimo es un impuesto variable en el transporte marítimo internacional que se asocia al transportar un contenedor de un puerto a otro. Sin duda, el flete marítimo es el coste más importante relativo al transporte internacional marítimo. Esta tarificación es un coste que varía en el tiempo y, además, en gran medida, por la oferta y la demanda. Existen otros muchos factores que también pueden condicionar este coste, como puede el tamaño del contenedor transportado que dependiendo de las dimensiones se aplicará una tarificación u otra. Además, también hay otros factores como el tipo de mercancía, el riesgo de la ruta, la rapidez del viaje, el factor de estiba o los gastos portuarios que se originan a lo largo de todo el servicio. No podemos olvidar que a la cantidad final del flete también se le puede sumar recargos por combustibles, cambio de monedas, cargos adicionales de distinta naturaleza o gastos de terminal. (stocklogisti, 2020)

Es un costo que varía en el tiempo y, además, en gran medida, por la oferta y la demanda. Existen otros muchos factores que también pueden condicionar este costo, como puede el tamaño del contenedor transportado que dependiendo de las dimensiones se aplicará una tarificación u otra. El precio del flete marítimo de un puerto a otro es un concepto que varía en el tiempo y fluctúa según la oferta y la demanda de las distintas rutas.

El concepto de flete anterior incluye los aspectos relativo a la oferta y a la demanda, la cual varía según factores como el tipo de mercancía, el riesgo de la ruta, la rapidez del viaje, el factor de estiba o los gastos portuarios que se originan a lo largo de todo el servicio. No podemos olvidar que a la cantidad final del flete también se le puede sumar recargos por combustibles, cambio de monedas, cargos adicionales de distinta naturaleza o gastos de terminal. 


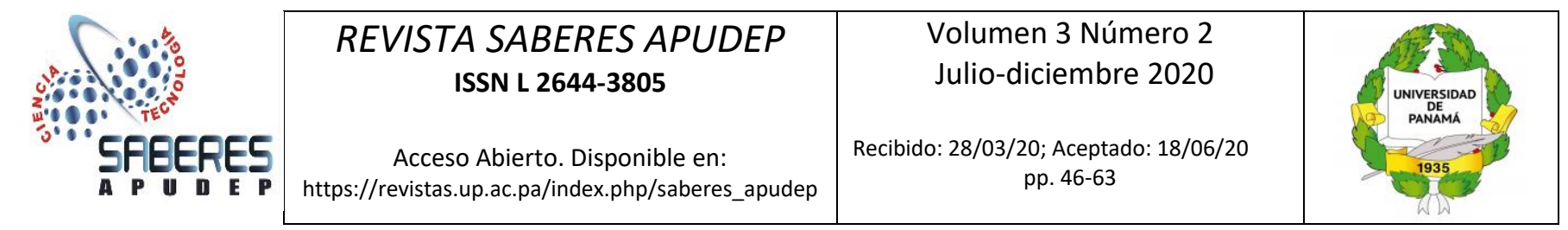

La tarifa del flete marítimo y lo incluida en la misma suele estar pactado entre el porteador y el usuario. Existen diferentes condiciones que son importantes a la hora de llevar a cabo esta negociación: transporte puerta a puerta, puerto a puerto, puerta a puerto o puerto a puerta. Cada una de estas cuatro opciones tiene su propia característica.

\subsection{Negociación de Fletamento}

Toda negociación implica la toma de decisiones, por lo tanto, se establece que es un proceso mediante el cual se realiza una elección entre las opciones o formas para resolver diferentes situaciones de la vida en diferentes contextos. La toma de decisiones consiste básicamente, en elegir una opción entre las disponibles, a los efectos de resolver un problema actual o potencial (aun cuando no se evidencie un conflicto latente).

La negociación de fletamento suele ser una de toma de decisiones que implica una labor de enfrentamiento de los intereses de los actores del negocio marítimo (armador, fletador, Bróker), se trata de una tarea que demanda de conocimiento, experiencia y especialización, tomando en consideración que las variedades y condiciones no suelen ser únicas, siendo así que se presentan realidades diferenciadas. En una negociación típica los niveles de conveniencia varían según el actor y la oportunidad de armonizar intereses suele ser una labor interesante que en ocasiones pueden resultar en la cancelación de una oportunidad de negocio.

El transporte marítimo en régimen de fletamentos se basa en la contratación de buques entre cargadores que necesitan transportar grandes volúmenes de mercancías y navieros que disponen de los buques apropiados para esa carga (tanto por sus características como por la situación geográfica del buque en cuanto a la fecha de embarque. 


\begin{tabular}{|c|c|c|}
\cline { 2 - 3 } & REVISTA SABERES APUDEP & Volumen 3 Número 2 \\
\hline
\end{tabular}

En el desarrollo de una negociación marítima de fletamento se debe especificar las condiciones en las que el Armador ó Armador Disponente realizaría el viaje, llegando a un acuerdo satisfactorio para ambas partes, sobre en los términos principales del contrato, donde suelen producirse la mayoría de las dificultades a la hora de negociar el fletamento y que son: el flete, la forma de pago y las demoras.

En el mercado del negocio marítimo y sus características de ser dinámico y de gran volatilidad, se puede dar que los ingresos obtenidos por armadores y los pagos a realizar por fletadores estén sometidos a importantes variaciones en periodos cortos de tiempo, por tanto, se trata de una revisión constantes de los cambios a fin de hacer los ajustes correspondientes y de satisfacción para los participantes. También se trata de un funcionar a un nivel de transparencia comprobada, donde la información fluye de marea continua ya la cual se tiene acceso inmediato para armadores y fletadores.

Con la accesibilidad y transparencia que la tecnología produce dentro de los procesos de negociación, las decisiones son cada vez en menor plazo de tiempo, lo cual hace fuerte la competencia y limita la comprobación de todos los términos y aun así se deben evitar los errores dado que pueden ocasionar graves consecuencias económicas, de allí lo importante de realizar negociaciones eficaces. La realización de un marco de referencia estándar, comúnmente aceptadas y bien conocidas por las partes, ha permitido simplificar las negociaciones.

En una negociación marítima de fletamento intervienen cuatro partes a saber: el Armador, el Fletador, el Bróker del Armador y el Bróker del Fletador. Al Armador y al Fletador se le denomina principales. Cuando un Armador inicia una negociación con un fletador desconocido es fundamental la obtención de referencias, como lo son anteriores embarques realizados y los Armadores con quien haya trabajado. Se da que en ocasiones cuando el Bróker del Fletador tiene buenas referencias es garantía suficiente ante el Armador. Hay que considerar que cuando 


\begin{tabular}{|c|c|c|}
\cline { 2 - 3 } & REVISTA SABERES APUDEP & Volumen 3 Número 2 \\
\hline \\
\hline A
\end{tabular}

se da el cierre del buque, el armador debe tener la certeza de que el Fletador es un pagador serio y puntual.

Contratos de trasporte:

1. Fletamento por Tiempo (Time Charter): es un acuerdo contractual por medio del cual el fletante pone un buque a disposición del fletador por un tiempo determinado en fecha y disposición convenidas a los efectos de que el fletador utilice el buque realizando viajes de acuerdo con el contrato corriendo con todos los gastos de explotación comercial (menos los inherentes a los gastos técnicos del buque) a cambio del pago de un alquiler cuya efectivización o normalmente se realiza en forma mensual o quincenal adelantado. El buque se arrienda con tripulación y elementos técnicos de seguridad y navegación, exceptuando el combustible que queda a cargo del fletador.

El arrendatario asume la Gestión Comercial durante un tiempo determinado y pago de un flete. El Arrendador, (Fletante, Propietario o Armador) se queda con la Gestión Náutica.

Obligaciones del Fletante:

- Poner el Buque a disposición del Fletador, en la fecha y lugar convenido, en estado de navegabilidad, salvo el desgaste.

- Pagar los gastos de la gestión náutica del Buque.

- Cumplir con las instrucciones y órdenes del Fletador.

- A efectos de la gestión náutica, el Capitán depende del Fletante. 


\begin{tabular}{|c|c|c|}
\cline { 2 - 3 } & REVISTA SABERES APUDEP & Volumen 3 Número 2 \\
\hline
\end{tabular}

Obligaciones del Fletador:

- Pagar el flete.

- Pagar los gastos inherentes a la gestión comercial.

- Utilizar lícitamente el Buque.

- Restituir el Buque en la fecha y lugar.

- Dar órdenes al Capitán en cuanto a la carga, transporte, entrega de las mercancías, personas y a la documentación.

2. A Casco desnudo (Bareboat Charterer): Es el contrato por el cual el propietario de un buque (locador), cede al locatario el uso o goce de aquel por un periodo determinado mediante el pago de un alquiler quedando el locatario a cargo de todos los gastos. El buque se entrega alistado para navegar sin tripulación ni combustible. Es usual que el fletante se haga cargo de los gastos de seguro de casco como una garantía adicional.

El arrendatario (Fletador) asume la Gestión Náutica y la Gestión Comercial del Buque por un tiempo y mediante el pago de un canon. El arrendatario adquiere la condición de Armador. El arrendatario no lo puede sub-arrendar o sub-fletar, sin la autorización escrita del arrendador.

Obligaciones del Fletante:

- Entregar el Buque en el lugar y tiempo previsto en estado de navegabilidad y con sus documentos.

- Efectuar las reparaciones previstas. Si no se puede utilizar el Buque, no se paga el canon. 


\begin{tabular}{|c|c|c|}
\cline { 2 - 3 } & REVISTA SABERES APUDEP & Volumen 3 Número 2 \\
\hline
\end{tabular}

Son obligaciones del Fletador:

- El aprovisionamiento del Buque, sus seguros, etc.

- Realizar reparaciones y reposiciones que no tengan origen en vicios propios del Buque.

- Utilizar lícitamente el Buque.

Responder ante el arrendador de todos los reclamos y privilegios como consecuencia de su gestión comercial. Devolver el Buque. Si no lo devuelve, luego de 15 días, pagara el doble del canon, salvo fuerza mayor.

3. Fletamento por Viaje (Voyage Charter): Es un contrato de fletamento en el cual el fletador arrienda al fletante la totalidad del porte neto sobre la base de un precio por tonelada de carga a embarcar, por un solo viaje y entre dos puertos con itinerario prefijado. Que comprende a varios de ellos. Se utiliza normalmente para carga granelera a granel y puede ser parcial o total, cuando la carga del fletador o cargador no llegue a completar el buque.

Puede ser total o parcial de los espacios del Buque susceptibles de ser cargados. Por un viaje o por varios. El Fletante conserva la Gestión Náutica y la Comercial y no puede sustituir el Buque, salvo acuerdo. El fletador debe pagar un flete por el o los viajes convenidos.

Son obligaciones del fletante:

- Presentar el buque en el lugar y fecha estipulada, en condiciones de navegabilidad, equipado y con la documentación requerida y mantenerlo así.

- Efectuar con diligencia el o los viajes convenidos. El Fletante es responsable de las mercancías. 


\begin{tabular}{|c|c|c|}
\cline { 2 - 3 } & REVISTA SABERES APUDEP & Volumen 3 Número 2 \\
\hline
\end{tabular}

Obligaciones del fletador:

- Proveer las mercancías.

- Asumir por su cuenta y riesgo las operaciones de carga y descarga, salvo pacto en contrario. El plazo de las estadías comienza cuando el buque ha arribado, listo para cargar o descargar, el fletante lo ha notificado por escrito al fletador y transcurra el lapso convenido; o en su defecto, el determinado por los usos del puerto, para el inicio de las actividades.

En los contratos de fletamento se debe establecer una cláusula de confidencialidad que obliga a las partes a mantener en secreto los términos de la negociación. Cualquier fletador quisiera conocer cuánto paga de flete un competidor suyo por el mismo transporte de carga, al igual que conocer el resto de términos del contrato de fletamento. Por otro lado, a los Armadores les gustaría conocer sobre el nivel de fletes que ofrecen sus competidores, dato importante a la hora de captar clientes. En la práctica esta confidencialidad se ve vulnerada muy habitualmente y poco después de realizar el fletamento ya se conocen las condiciones acordadas.

Los términos de la negociación se rigen principalmente por la Oferta y Contraoferta se trata de un cruce de ofertas y contraofertas hasta dar con un punto de equilibrio de conveniencia. La forma más común y con referencias éticas es ofertar para un negocio determinado y no lanzar ofertas a varios negocios que tienen posibilidad de materializarse y que podrían aceptarse a la vez, con los problemas que esto implicaría. De allí que lo corrector deberá ser expirar una oferta antes de optar a otra, lo cual no siempre se cumple especialmente en los buques de tonelaje bajo. 


\begin{tabular}{|c|c|c|}
\cline { 2 - 3 } & REVISTA SABERES APUDEP & Volumen 3 Número 2 \\
\hline \\
\hline A
\end{tabular}

En el lenguaje habitual del intercambio de ofertas y contraofertas, encontramos los siguientes términos:

> Accept / Except: significa que la parte que recibe la oferta o contraoferta acepta alguna de las condiciones de la oferta, pero no todas, por lo que en su contraoferta posterior figurarán sólo aquellos puntos en los que discrepa, claro está indicando sus pretensiones.

> Repeat last offer /except: ya avanzada la negociación tras recibir la última propuesta, se indica que se mantiene o remite a la última oferta o contraoferta facilitada, pero cambiando algunos términos que pueden ser concesiones a la otra parte o nuevos requerimientos.

$>$ Decline your offert and offer: supone el rechazo total de la oferta una de las partes y contraoferta con términos totalmente distintos.

Al producirse un acuerdo en estos términos y se dan las oportunas confirmaciones, se cuenta con un acuerdo firme (fixture), el cual por norma general suele declararse hasta después de una hora determinada, para luego declarar un cierre limpio (clean), si alguno de los sujetos falla y no se pudiese declara "clean fixture" por algún motivo, se supondrá que lo acordado no tiene validez sin que por ello se dé ningún perjuicio para algunas de las partes.

El Armador estará interesado en reducir el tiempo acordado para declarar los sujetos y los más comunes son:

$>$ Sujeto a Stem (subject to stem): se debe verificar con todas las partes que la carga estará disponible para su carga. 

REVISTA SABERES APUDEP
ISSN L 2644-3805

Acceso Abierto. Disponible en:

https://revistas.up.ac.pa/index.php/saberes_apudep
Volumen 3 Número 2

Julio-diciembre 2020

Recibido: 28/03/20; Aceptado: 18/06/20 pp. $46-63$

> Sujeto a aprobación del cargador (subject to shippers approval): el fletador debe comprobar que el buque es aceptable en la terminal de carga y que la carga estará disponible para ser cargada en las fechas pactadas.

> Sujeto a aprobación del receptor (subject to receivers approval): el fletador debe obtener la aceptación del puerto o de la terminal de descarga al buque, a su llegada estimada y a la cantidad a cargar, antes de levantar los sujetos.

> Sujeto a venta (subject to sale): la venta de la carga está siendo negociada y una vez se confirme se "levantaran los sujetos" para su transporte.

> Sujeto a la aprobación de los fletadores por armadores (subject to owners approval of charterer) si el fletador es desconocido el Armador podrá dejar sujeta a la confirmación del cierre a las investigaciones sobre la credibilidad y la solvencia del mismo este realizando.

> Sujeto a detalles (subject to details) se suele incluir al final del recap cuando ya se han negociado los términos principales de un cierre "main terms", quedando así el fletamento sujeto a determinar otros detalles menos importantes pero necesarios.

\subsection{Términos del Cierre}

El Cierre de la negociación de fletamento implica un conjunto de aspectos, entre el que sobresale como el nombre y descripción de buque. Es fundamental proporcionar descripción detallada, completa y fiable del buque, aunque estamos claro que la función del Bróker es comprobar la fiabilidad de los datos que su principal le ha transmitido, al final de la descripción se emplean términos como "all details abt, and wog", que indica que "todos los detalles son aproximados y sin garantía".

La descripción del buque es una de las primeras cosas que el Fletador o su Bróker solicitan, con esto busca comprobar y continuar con la negociación, que el 


\begin{tabular}{|c|c|c|}
\cline { 2 - 3 } & REVISTA SABERES APUDEP & Volumen 3 Número 2 \\
\hline
\end{tabular}

buque es apto para la carga que se quiere transportar. El Armador, Armador Disponente o su Bróker no tendrán inconvenientes en proporcionar los detalles del buque que sean necesarios para que no se dé obstáculo en las negociaciones.

En la mayoría de los casos el Armador seguido del nombre del buque aparezca "or subs", es decir, "o substituto", de esta forma el amador se reserva la posibilidad de sustituir el buque por otro similar en tiempo y lugar, con esto se da flexibilidad al Armador o Armador Disponente.

El transporte marítimo ha presentado cambios importantes que han beneficiado significativamente su desarrollo como un negocio altamente importante para el comercio mundial, sin embargo, no podemos dejar de considerarlo como una aventura, por más que con el paso del tiempo se hayan controlado más variables, y programar con la exactitud que requieren algunos fletadores, de allí que algunos desarrollan negociaciones complejas y satisfactorias para las partes.

La segunda parte del cierre de negociación es la que nos indica por cuenta de quién se realiza el embarque, es decir, a quien se identifica como Fletador, que no siempre tiene que ser el verdadero Fletador (cuando se dice verdadero Fletador se hace referencia a aquel que realmente tiene la necesidad de realizar el transporte). Es importante por ello se hace el señalamiento de la buena reputación de un Fletador en el mercado, el llamado "background". Ser un Fletador respetado supone que se presuponga la seriedad, principalmente en el pago del flete que es la principal obligación de todo Fletador, sin embargo, es común que los más grandes e importantes Fletadores quiera que figure una sociedad offshore, ubicada en un paraíso fiscal, y es en estos casos donde se convierte en esencial para el Armador tener la garantía de cobro del flete. 


\begin{tabular}{|c|c|c|}
\cline { 2 - 3 } & REVISTA SABERES APUDEP & Volumen 3 Número 2 \\
\hline
\end{tabular}

Lo anterior es con independencia de que el Bróker en algunas ocasiones pueda aparecer también como Fletador o incluso como garante del pago del principal, sobre todo si la reputación del Bróker es más sólida que la del Fletador, así el Armador, Armador Disponente o su Bróker no tienen por qué conocer al Fletador ya que con la garantía de su Bróker es más que suficiente, esto es una práctica habitual en los tráficos de cabotaje, pero en los embarques transoceánicos, de buque de gran tonelaje (Panamax, Neopanamax y Suezmax), donde los fletes suponen millones de Euros o Dólares, un Fletador que no pague puede ocasionar un enrome daño, por lo que las precauciones son mayores y las referencias del Fletador y Bróker deben ser consistentes y ofrecer total confianza, de otra forma los armadores ni siquiera iniciaran los contactos.

Con relación al atraque se establece "one good safe berth always afloat", es decir un único atraque seguro y siempre a flote. El atraque seguro establece que el Fletador tratará de designar puertos o lugares seguros, pero sólo con esta indicación no implica la seguridad de los lugares de atraque por lo que la responsabilidad final, sigue recayendo en el Armador o Capitán, para evitar percances se suele indicar "Always safely afloat, siempre en seguridad a flote. Lo que evita que el buque pueda atracar en muelles en los que no pueda cargar o descargas sin tocar el fondo.

En ocasiones no se puede especificar claramente el puerto de carga y descarga. Se dan casos en los que el Fletador tiene la opción de carga o descargar en varios puertos, por lo que solicita del Armador, Armador Disponente o su Bróker durante la negociación que le cotice para el embarque pensando en la posibilidad de descarga en cualquiera de las opciones planteadas. De esta forma se vuelve muy importante determinar, quien decide el orden de la carga o descarga en los distintos puertos, si el Fletador (Charter option, chopt) o Armador (Owner option, oo) o si se decidirá de mutuo acuerdo entre las partes. Se puede dar el caso en el que el buque salga del 


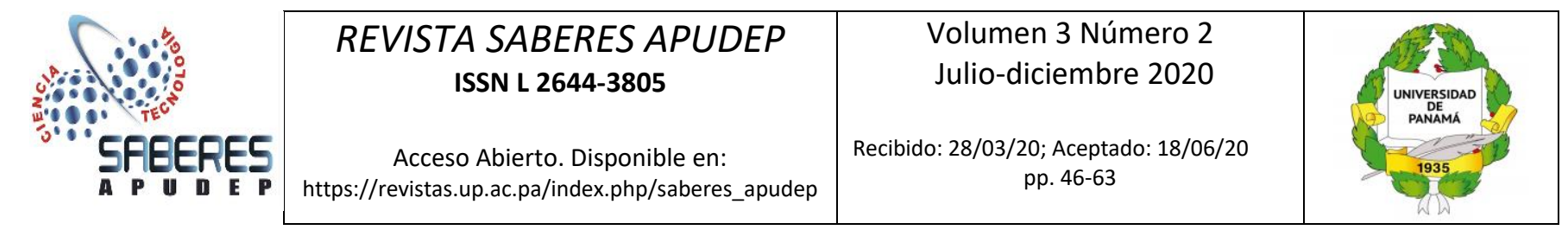

puerto de carga y todavía no sepa el puerto exacto de descarga, sino simplemente un rango geográfico, que el Fletador le ha facilitado al Armador y por el que este le ha ofertado o bien saber los puertos de descarga, pero ignorar el orden.

\section{CONCLUSIÓN}

El fenómeno de la globalización en la vida económica contemporánea, aunada a las grandes oportunidades que brindan las nuevas tecnologías en comunicación y los flujos financieros, permite que el comercio internacional de importación y exportación se haya convertido en un espacio de negociación del transporte marítima de grandes proporciones en cuanto a las nuevas formas comerciales que revisten el fletamento.

El Contrato de Fletamento puede ser conceptualizado como el acuerdo de voluntades entre partes, una de las cuales se compromete a poner a disposición de otra un buque para la transportación de las mercancías o a efectuar la transportación de las mismas que en contraprestación recibe a cambio una cantidad de dinero llamada flete. No obstante, lo anterior el Derecho Marítimo moderno se opone a que el fletamento se acepte como un arrendamiento ya que el depósito de las mercancías en el buque no constituye un almacenamiento y si un acto indispensable para la transportación de estas desde un punto a otro sobre el agua.

El Contrato de Fletamento es por su carácter eminentemente consensual no obstante su formalización escrita. El consentimiento es su forma de perfeccionarse. El Contrato de Fletamento es un acto propiamente mercantil. Se indica que el fletamento cumple con una labor de facilitación del comercio internacional, sustentado en la investigación del mercado y la toma de decisiones para cumplir con el proceso integral de todo el proceso de fletar buque por viaje, con la participación de sus actores principales (Armador, Armado Disponente, Bróker y Fletador). 


\begin{tabular}{|c|c|c|}
\cline { 2 - 3 } & REVISTA SABERES APUDEP & Volumen 3 Número 2 \\
\hline
\end{tabular}

\section{REFERENCIAS BIBLIOGRAFICAS}

BAENA, J. (noviembre de 2002). «Capítulo 5. Transporte marítimo». En Fundación EMI-Manresa. Transporte internacional (primera edición). Barcelona (España): Logis Book.

Cabrera CÁnovas, A. (2011). «Capítulo 5. Contratación del transporte marítimo. Contratación del Transporte Nacional e Internacional de Mercancías. Adaptado a las Reglas Incoterms 2010. Madrid (España): Fundación Confemetal.

Carmona PAstoR, F. (2005). Capítulo 1. Transporte marítimo». Manual del transportista (Primera edición). Madrid (España): Díaz de Santos, S.A.

Convenio de Hamburgo de 1978. UNCITRAL. Transporte Marítimo por Línea Regular o de Conocimiento.

Chami, D. (2010). Manual de Derecho de la Navegación, Abeledo Perrot, Buenos Aires, 2010.

Álvarez-Correa, (1984). Contrato de fletamento marítimo, Guías de clase, Posgrado de Contratación Internacional, Universidad de los Andes.

Guzmán, J.V. (2007). El contrato de transporte marítimo de mercancías bajo conocimiento de embarque, Bogotá, Universidad Externado de Colombia.

Laudo Arbitral Instituto de Mercadeo Agropecuario (IDEMA) contra COLMARES LTDA. Y TMM S.A. DE C.V. Árbitros: Rafael H. Gamboa Serrano, Luis Helo Kattah y Ramiro Bejarano Guzmán, Bogotá D.C., 28 junio de 1993.

Laudo Arbitral: Instituto de Mercadeo Agropecuario (IDEMA) contra

Colmares Ltda. y Transportación Marítima Mexicana S. A. de C. V. Árbitros: CARLOS URRUTIA HOLGUÍN, CARLOS HOLGUÍN y ÁLVARO MENDOZA RAMÍREZ, Bogotá, D. C., 9 marzo de 1994

Mira GalianA, Jaime; Soler García, David (2010). Gestión del transporte.

Manual práctico para la gestión integral del transporte de mercancías. Biblioteca de Logística (Primera edición). Barcelona (España): Marge Books. 


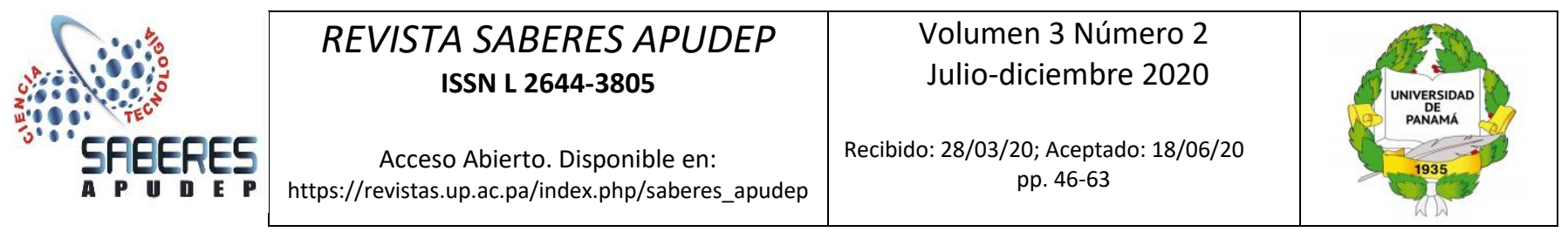

Manual del transporte marítimo. Biblioteca de Logística. Con la colaboración de Logisnet (Primera edición). Sabadell (Barcelona, España): Marge Book

Romero Serrano, Rosa (2002). Capítulo VI. Contratos de transporte marítimo». En Centro Intermodal de Logística, S.A. (Cilsa) e Instituto de Logística Iberoamericano. 